\title{
Strategic planning and decision support in small-medium wood enterprises using database technology
}

\author{
Andreopoulou Zacharoula ${ }^{1}$, Koliouska Christiana ${ }^{2}$, Tsekouropoulos Georgios ${ }^{3}$
}

\section{N F O}

Received 01 Jun. 2012

Accepted 13 Jun. 2012

Available on-line 15 Jun. 2012

Responsible Editor: K. Rajkai

\section{Keywords:}

DBMS,

wood SME enterprise,

database technology,

strategic planning,

decision support

\begin{abstract}
A B S T R A C T
As the enterprise management plays vital role in the overall performance of a company, it is recognized the need for application of quality improvement tools and techniques such as database technology. A DataBase Management System (DBMS) is an IT application, which contains information about the company in various levels. Enterprises can use DBMS to plan and standardize their practices and increase overall efficiency in the company. It is an essential management tool for Small and Medium-sized enterprises (SMEs) because in such companies the entrepreneur-owner is personally responsible for managing the activities of the company without being an expert. This modern information technology tool is the basis of the application of marketing principles and techniques via electronic media and more specifically the internet. The purpose of this paper is to explore how implementation of modern information technology tools, such as DBMS, simplifies SME management. That DBMS design approach can be a useful tool while designing similar applications in SME in wood sector and also in various issues in primary and secondary production sector.
\end{abstract}

\section{Introduction}

SMEs are critical to the economies of all countries (Akhavan and Jafari, 2008), and especially the developing ones (Fathian, Akhavan and Hoorali, 2008; Gadenne and Sharma, 2009). Thassanabanjong, Miller and Marchant (2009) identify that they are crucial for sustained, long-term growth, dynamism and employment. SMEs are regarded as one of the main driving forces of economic development, stimulating private ownership and entrepreneurial skills (Gadenne and Sharma, 2009). The entrepreneur-owner, in such type of companies, has to take care of the strategic management competence of the company. Strategic management competence can be defined as "a company's ability to involve different actors in the strategy process, characterized by the formalization and use of different strategic tools (Kohtamaki, Tornikoski and Varamaki, 2009).

In SMEs, decision-making processes are not very regularized, rather are very centralized and based on the experience, personal knowledge and intuition of the people in the key roles in the company (Garengo et al., 2005). Also, at post assessment stage, "weighting” each criterion is a very difficult process and depends heavily on the personal preference of the decision maker (Hu, Abley and Zou, 2008). It is also supported that people by and large manage organizational complexity intuitively and of course in the process they make more or less costly mistakes (Espejo, 2008).

Assimakopoulos, Dimitriou, and Theocharopoulos (2010) in their research on business intelligence systems for virtual enterprises summarise that the modern business environment requires fast, efficient and reliable management of vast amounts of information and diverse data. Therefore, the adoption of new technologic solutions and innovative managerial practices are needed, which will offer flexibility, immediate feedback and short decision-making capacity. So, these optimization methodologies and

\footnotetext{
${ }^{1}$ Andreopoulou Zacharoula

Aristotle University of Thessaloniki

randreop@for.auth.gr

${ }^{2}$ Koliouska Christiana

Aristotle University of Thessaloniki

ckolious@for.auth.gr

3 Tsekouropoulos Georgios

Alexander Technological Educational Institution of Thessaloniki

gtsek@acc.teithe.gr
} 
frameworks will increase the effectiveness and the quality of crucial activities like spatial analysis, strategic objectives setting, long-range planning and decision-making. Respectively, this effect will improve the overall performance of the company and will enhance the potentials for growth development of economy (Sagheb-Tehrani and Manousaridis, 2007). In recent studies on software project management and planning, it is concluded that “...the use of modern management techniques and state-of-the-art tools are some of the most important factors that affect the competitiveness of the companies" (Chatzoglou et al., 2007). Management has increasingly paid attention to the reuse of historical data that reflect changes of customers, suppliers and organizations themselves. In consequence, many organizations are continuously attempting to look for advantageous connections between organizational variables and use preference of data-based decision support technology (Wu, Kao and Wu, 2006).

\subsection{Database Management System}

In a modern SME, innovative technology tools, internet, intranets and databases usually have important roles (Andreopoulou et al., 2008; Tsekouropoulos et al., 2011). Applying these systems, enterprises struggle to realize business opportunities in highly competitive markets. In this setting, the integration of existing information systems is becoming more and more indispensable in order to dynamically meet business and customer needs while leveraging long-term investments in existing IT infrastructure. In general, integration of different information systems aims at combining selected systems so that they form a unified new whole and give users the illusion of interacting with one single information system. The reason for integration is twofold: First, given a set of existing information systems, an integrated view can be created to facilitate information access and reuse through a single information access point. Second, given a certain information need, data from different complementing information systems is combined to gain a more comprehensive basis to satisfy the need (Ziegler and Dittrich, 2007).

The DBMS environment was designed in a specific way in order to follow some basic principles. These principles are: availability, reliability, scalability, manageability, security and flexible solutions. The aim of databases is to store facts of a mini-world in an information system. A lot of facts are not static but they change over time. Facts are not valid forever but they are valid in the real world for a certain period of time. The frequency of changes ranges from years to milliseconds or even beyond. A name of person changes very rarely but a share price changes several times during a minute. A wide range of database applications are temporal in nature and manage time-varying data. Database storing only the current facts about the mini-world are called 'snapshot databases', while databases which store the course of facts, as they change over time, are called 'temporal databases' (Schlaginhaufen, 2007). So, a temporal database maintains past, present and future data (Tansel, 2009). They underpin all the activities of a library management system by providing the basic storage and retrieval technology. The library application software sends data to and receives data from the DBMS which is hardly noticed at all.

The total approach of data entry in a database has many advantages, such as independence structure from other applications, reduction in duplicate record creation and data accuracy because of automatic data update (Mc Fadden, Hoffer and Prescott, 1999). Databases offer access and handling to a vast amount of data, collection of relevant data, independent data processing, common view of the database, increase in productivity and reduction in delay time (Elmasri and Navathe, 2004). They also help the user to a more effective data handling, thanks to an interface environment that is designed for database adjustment to the user's needs and requirements through browsing the appropriate buttons until showing the desired results (Pratt and Adamski, 1991; Post and Kagan, 2001; Elmasri and Navathe, 2004).

The data stored in a DBMS package can be accessed by multiple users and by multiple application programs like SQL Server, Oracle and Microsoft Access. Jeffery (2008) found that the essential feature of database technology is that it provides an internal representation (model) of the external world of interest. DBMSs also offer multi-processor support, support for parallel queries and clustering. The implementation of a DBMS will provide the company with better management, control of the company's inventory and productivity improvement. Typical examples of DBMS package use 
include accounting for quicker and more efficient operation, human resources for maintaining information of either employees or applicants to job openings and finally, customer support systems for better understanding and quicker response to customer needs. Darwish (2009) states that:

"a customer database can form the coherent management of relationships with customers. This customer relationship management plays an important role in many business' sales and marketing strategies.”

Database technology also underpins all activity in the area of production engineering, from scheduling workflow through the production lines of machines to stock control and order processing (Jeffery, 2008).

Every SME knows the value of a customer database as a sales and marketing tool. Used properly, the customer database is one of the most potentially effective devices to reinforce customer loyalty and boost sales (Lloyd, 2007). DBMSs have more recently emerged as a fairly standard part of any company back office. Sales and marketing would be impossible without good database systems (Lloyd, 2007). The essential point is that DB system is generic, and the functionality it provides can serve a large variety of sectors (Sohrabi, Jafarzadeh and Ahmadabadi, 2010).

Some library system suppliers are continuing to maintain and develop their own DBMS. This may seem anachronistic but there are some substantial advantages. The DBMS can be totally designed around the problems and idiosyncrasies of the library application. Furthermore, inverted indexes can be built in. the speed of response to problems will be also increased. If a problem arises with a proprietary database, the company can usually fix it more quickly than bigger company where a small problem may not get priority (Vowles, 2001).

\subsection{Database Technology and E-marketing}

Nowadays, the Internet, apart from a channel to collect information of all kind (Tsekouropoulos et al., 2011), offers companies the opportunity to market goods and services to more customers than ever before (Griffin, 2000). The enterprises aim at their participation in the internet society since the benefits are high and electronic systems are ready to serve customers all over the world 24 hours per day and 7 days a week (Andreopoulou, 2008), when the cost keeps decreasing (Tsekouropoulos et al., 2011).

Eszes (2010) defines e-marketing as the use of Internet and related digital technologies to achieve marketing objectives and support the modern marketing concept. It includes both direct response marketing and indirect marketing elements, and uses a range of technologies to help connect businesses to their customers. By such a definition, e-marketing encompasses all the activities a business conducts, such as: business intelligence, customer relationship management, supply chain management, e-commerce and enterprise resource planning (Tsekouropouloset al., 2012), via the worldwide web with the aim of attracting new business, retaining current business and developing its brand identity (Quirk eMarketing, 2006). E-commerce is the purchasing, selling, and exchanging of goods and services over computer networks, such as the Internet, through which transactions or terms of sale are performed electronically. E-commerce can be broken into four main categories: Businessto-Business (B2B), Business-to-Consumer (B2C), Consumer-to-Business (C2B) and Consumer-toConsumer (C2C) (DigitSmith, 2006). E-marketing and e-commerce are subsets of e-Business that utilizes electronic medium to perform marketing activities and achieve desired marketing objectives for an organization (Petrovic, 2010). E-business expresses the continuous improvement of the services of an enterprise through digital technology (Tsekouropoulos et al., 2011).

E-marketing gives business of any size access to the mass market at an affordable price and allows truly personalized marketing. Specific benefits of e-marketing include The Department of Trade and Industry of United Kingdom (2004) and The National B2B Centre (2011) suggest that the benefits of e-marketing are the following:

- Global reach. A website allows finding new markets and trading globally. 
- Lower cost. A properly planned and effectively targeted e-marketing campaign can reach the right customers at a much lower cost than traditional marketing methods.

- Trackable, measurable results. Web-analytics and other online metric tools make it easier to establish how effective the campaign has been.

- 24-Hour marketing. With a website the customers can find out about the products even if the office is closed.

- Shorter lead times. If there is a website or an e-mail template, the reaction to events will be more quickly, giving a much more contemporary feel.

- A level playing field. With a well-designed website, the enterprise could look like professional and credible as the larger competitors.

- Personalization. If the customer database is linked to the website, then whenever someone visits the site, can be greeted with targeted offers.

- Openness. By having a social media presence and managing it carefully, the entrepreneur can built customer loyalty and create a reputation for being easy to engage with.

- Social currency. E-marketing lets the entrepreneur create engaging campaigns which can gain social currency-being passed from user to user and becoming viral.

- Improved conversion rates. If the enterprise has a website, then the customers are only ever a few clicks away from completing a purchase.

Together, all of these aspects of e-marketing have the potential to add up to more sales.

However, e-marketing does have few disadvantages such as (Eszes, 2010): lack of personal approach, dependability on technology, security-privacy issues, maintenance costs due to a constantly evolving environment, higher transparency of pricing, increased price competition and worldwide competition through globalization.

The first thing in building any e-commerce application is creating the underlying database to support it (Curtis, 2000). So, having already a well-maintained database of the enterprise, a website of an e-market place could be easily designed, for taking advantage of all the privileges given by the internet such as advertising, promotion or low cost.

This paper discusses the use of this modern information technology tool, DBMS and will be described how it simplifies management in the case of a wood SME in terms of strategic planning and decision support.

\section{Methodology}

This database model was entirely developed with Microsoft Access 2007 using Intel Core Duo $2 \mathrm{GHz}$ processor, where Windows 7 are being run. The total archive occupies $1.03 \mathrm{MB}$.

Data collection was made straight from the entrepreneur's books, the clientele and the employee's archives. The 10 tables that were created are the following:

- Customers. It includes all the personal data of each customer such as name, date of birth, address and phone. This table sets the customer ID.

- Statements. It involves details about the transactions such as the ID of the customer that made the order, the product ID, the order month, the number of the days of manufacture, the price of the product and the receipt type.

- Materials. In this table, can be found information about the materials that have been used, the type of wood and the country of its origin. This table defines the material ID.

- Payment-Delivery. This table indicates not only which orders have been paid but also which orders have been delivered. 
- Products. Here, the product ID is set. The type of furniture and its material ID are also mentioned.

- E-mail Addresses. This table shows the customer ID and whether he has an email address or not. If he has, it is written.

- Providers. Which the provider of each material is, is displayed.

- Staff. This table holds personal details of all the employees, such as their names, their addresses, their phones. There are also information about the expertise of each one, his months of experience and his monthly salary, too.

- Shippers. It says what shipping companies are used, their phone number and their URL. The shipper ID is also set.

- Shipping details. Here, the customer ID, the shipping address, the city, the region and the postal code are mentioned.

At our convenience, some items have been encoding. Each customer, each employee, each product, each shipper and as well as each material, has its own unique serial number that is displayed as ID.

Then, the relationships among the tables were defined. It is essential to establish the relationships within the relationship view in Microsoft Access for a well-rounded and finalized project in order to protect the data from orphaned records. Tables are linked so that all information is consistent across the entire database. So, we can create queries to display information from several tables at once.

After the creation of the relationships, several queries were made, which meet the manager's needs and help strategic planning and decision support within company. More specifically, a Microsoft Access query is a useful tool when it comes to accessing data from an already built database. The user often calls them by means of a form. These queries have a great number of uses, such as searching for and obtaining data from one or more of the existing tables, performing certain actions inside the database or making certain calculations, depending on the user's needs. The design of Microsoft Access operates in such a manner that it accepts different types of queries. One could consider these queries as just another part of one's database, almost like an object such as a macro or a table.

The select query, one of four types, is the easiest and simplest. Due to this fact, it is also the most frequently used in Microsoft Access databases. Depending on the user's needs, this Microsoft Access query is useful in selecting and then displaying data from one or from more of the tables existing in the database. The user can also create a temporary table where he can operate changes in data, but he cannot perform this action for more than one record at a time (Wilson, 2007).

Printable reports from queries were further developed, aiming to support managerial tasks.

\section{Results}

Having added all the data collected from the SME, the 10 tables are full. Figure 1 indicates which tables are linked and which particular fields of them. The primary key of each table can be seen, too. Each table is required to have a primary key in order to interact with other tables. For instance, a customer may have many orders. The customer's private information is held in a table separate from the order information. A relational database setup with referential integrity prohibits the deletion of a customer record without first deleting the associated orders. This creates data integrity by eliminating orphaned records. 


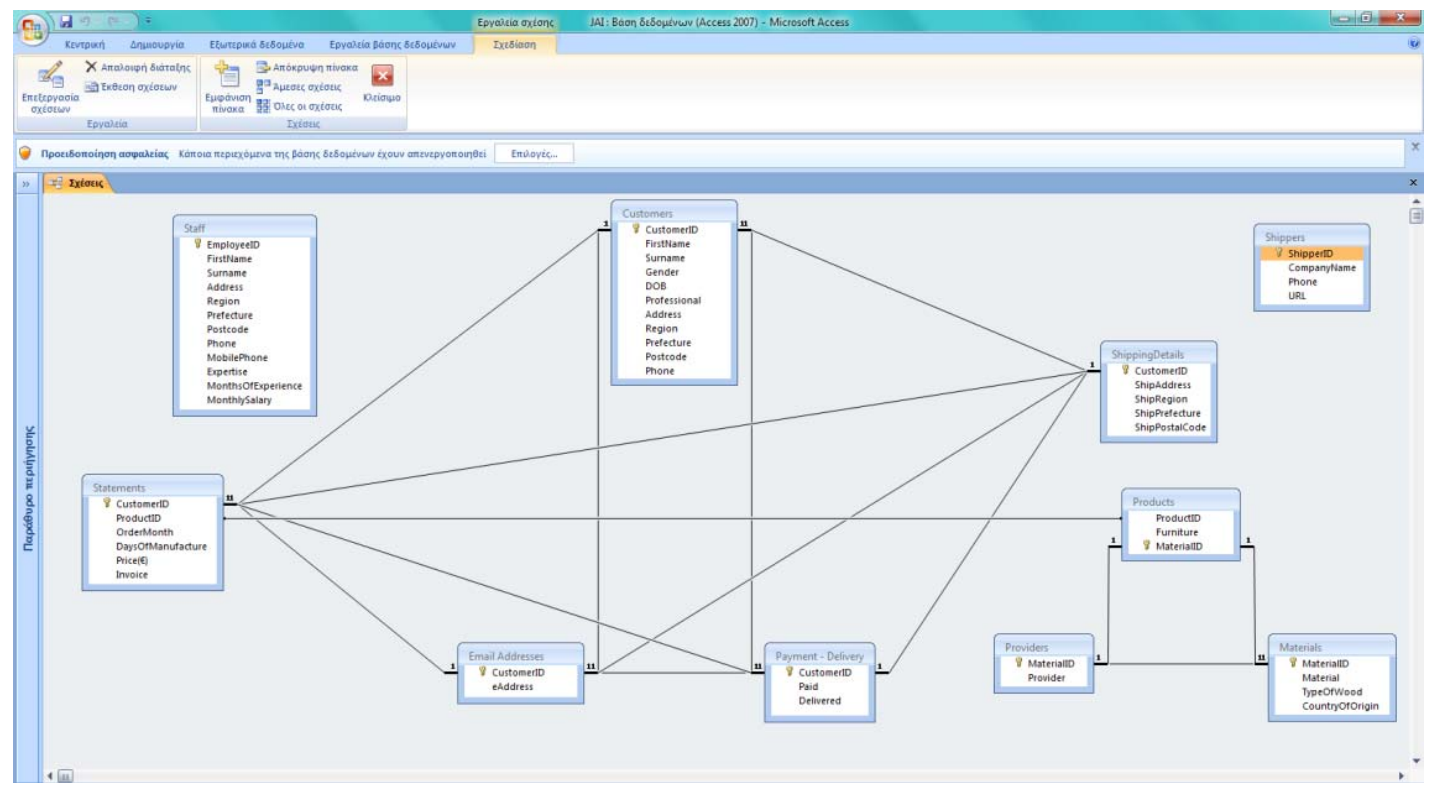

Figure 1. The relationships among the tables

Figure 2 displays indicatively the final table "Shippers".

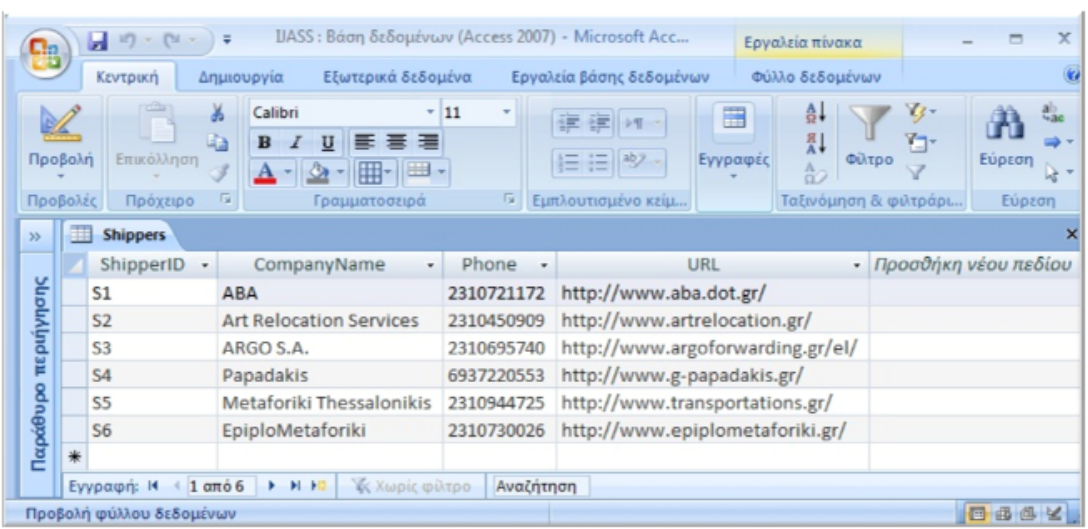

Figure 2. Final Table "Shippers"

Figure 3 introduces the final table with results of the query "How long does it take for furniture to manufacture?”

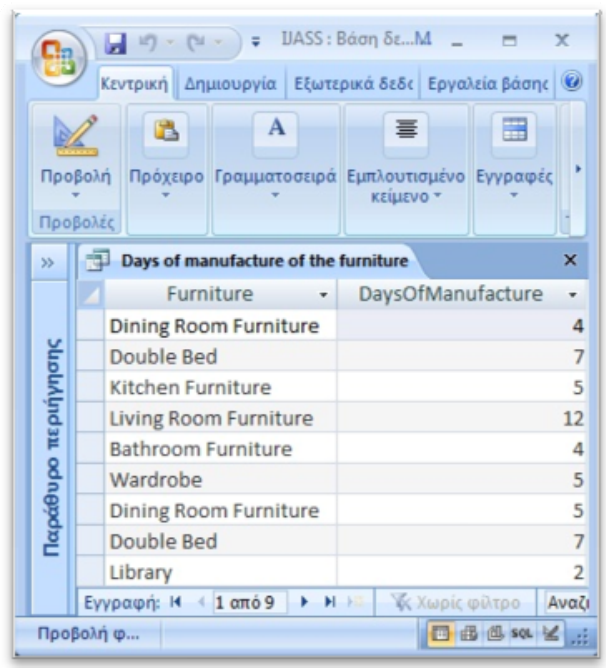

Figure 3. „Days of manufacture of the furniture” 
Further queries have been created that cover the needs of the enterprise. The Table 1 shows all the query tools used in the DBMS and their accomplished functions.

Table 1. Query tools of the DBMS

\begin{tabular}{|c|c|c|}
\hline & Query tool & Function accomplished \\
\hline 1 & Employees' salaries & Awareness of the company financial duties to its staff \\
\hline 2 & $\begin{array}{l}\text { Customers that have requested Greek } \\
\text { wood }\end{array}$ & $\begin{array}{l}\text { Decision for continuation or not of the collaboration with Greek } \\
\text { providers after demand specification of Greek wood }\end{array}$ \\
\hline 3 & Earnings 2010 & Knowledge of the statement of the financial position \\
\hline 4 & $\begin{array}{l}\text { Orders that have been placed during } \\
\text { summer months }\end{array}$ & Achievement of better staff management during summer months \\
\hline 5 & $\begin{array}{l}\text { Professionals that have not requested } \\
\text { invoice }\end{array}$ & Knowledge of the immediate professionals' cash payments \\
\hline 6 & $\begin{array}{l}\text { Customers that do not live in } \\
\text { Thessaloniki }\end{array}$ & Evaluation of the need for co-operation with a common carrier \\
\hline 7 & Customers that have an email address & Easier and more effective type of communication \\
\hline 8 & Orders that have been delivered & Better delivery scheduling \\
\hline 9 & Statements that have been paid & Knowledge of the statement of financial position \\
\hline 10 & Artificial materials that have been used & $\begin{array}{l}\text { Acquaintance with the types of artificial materials that have been } \\
\text { consumed }\end{array}$ \\
\hline 11 & Materials that have been used & Acquaintance with the material types that have been consumed \\
\hline 12 & Days of manufacture of the furniture & $\begin{array}{l}\text { Providing the right information to the customers how many days of } \\
\text { manufacture of the furniture }\end{array}$ \\
\hline
\end{tabular}

Taking into account the queries about the orders which have been delivered and the statements which have been paid, the entrepreneur can become acquainted with the accomplished statements. In this way, knowing the abeyances of the company, he will create a better strategic plan. Only when actual outcomes meet or exceed strategic goals the entrepreneur knows that his plan is on target and that it is being implemented effectively. Generally, a good plan has the following attributes (Pearson, 2008): 1. A swot analysis of firm's is true strengths and real-world weakness. It is also important to look on the horizon of change and think through the opportunities and competitive threats in the markets. 2. An analysis of the personnel's strengths and weaknesses. 3. An analysis of the forces that come from the outside. 4. Identifying and stating clearly the vision, mission, and values of the company. 5. Finally, setting goals, both realistic and stretch.

Additionally, having created queries about the 2010 earnings, the statements that have been paid and a table that contains detailed information about the staff (including monthly salary of each employee), the entrepreneur can evaluate accurately the financial situation of its entire company. Understanding and evaluating company position in terms of its finances, is the first step in taking action and developing any sound investment plan (Haramis, 2009).

Furthermore, decisions about better staff management respecting the summer vacations can be facilitated knowing the number of orders during the summer months through a query. The employees are the number one asset so allowing so, allowing them to take as much of their earned vacation as possible will go a long way when they are at work. 
Also, the entrepreneur is capable to be familiar with the consumption of each staple and as a result with the need of feedback, through the suitable tables and queries. So, he will never again either order big quantity of the staple that is not used so often or order smaller quantity of this one that is used more.

As well, the entrepreneur can be informed immediately about its customers' personal information such as its address, the email address, the furniture type that has ordered. In case there is an email address, the entrepreneur could inform the client about either special offers or simple advertisement emails. Using email newsletters, stronger relationships will be built with the existing customers. It impacts business in a positive way and has the edge over other methods of communication (Geld, 2003).

Last but not least, DBMS gives the entrepreneur the capacity of enhancing the competitiveness of its firm. This decision support system helps the company to deliver its products at the right time, to the right place and with the right price. So, it is more feasible for the enterprise to survive in the competitive marketplace (Ho et al., 2007).

Finally, it is worthwhile to note that we have added buttons, in the Access main window, that run these queries using the criteria that have been entered in the form fields. Printable reports are also connected.

\section{Conclusion}

DBMS can be a basic improvement tool for a SME in a variety of sectors. It offers a fruitful approach for avoiding failure as it displays the required information for each situation. So, the entrepreneur is able to make the right decisions in least possible time. It is worthwhile to note that it is not very time and effort consuming for creating a database like this. With the proper way of use, this system can also help company lower its operating costs.

SMEs could use DBMSs to plan and standardize their practices to increase overall efficiency in the company. In this paper, the DBMS model for SME that was proposed was achieved because DBMS can facilitate the entrepreneur in the decision-making of each enterprise sector.

The described DBMS was created using Intel Core Duo 2GHz processor, where Windows 7 are being run. The model was developed with Microsoft Access 2007 which belongs to the Microsoft Office 2007 package. The total archive occupies $1.03 \mathrm{MB}$ and it is possible to be transferred to another pc and to be edited, on condition that Microsoft Access 2007 or other version of Microsoft Office has been installed.

As a future extend, more tables can be created for the sectors the manager is interested in. More relationships, queries, reports and filters can be made in order to serve manager's needs. Moreover, a website could be created with this database as its basis for e-commerce activities, business to business (B2B), business to customer (B2C), even supply chain management. In a recent research (Andreopoulou, Koutroumanidis and Manos, 2009), the adoption of e-commerce in wood enterprises in Greece is described. Given some basic computer expertise by the entrepreneur, and DB software, the overall performance of the company will be optimized.

\section{References}

Akhavan, P. and Jafari, M. 2008. Towards learning in SMEs: An empirical study in Iran. Development and Learning in Organizations. 22:(1) pp.17-19.

Andreopoulou, Z.S. 2008. Computer Networks, Sustainability and Environment. University lectures. Aristotle University of Thessaloniki.

Andreopoulou , Z., Koutroumanidis, Th. and Manos, B. 2009. The adoption of e-commerce for wood enterprises. International Journal of Business Information Systems. 4:(4) pp. 440-459.

Andreopoulou, Z., Tsekouropoulos, G., Koutroumanidis, T., Vlachopoulou, M. and Manos, B. 2008. Typology for e-business activities in the agricultural sector. Int. Journal of Business Information Systems.3:(3) pp.231-251. 
Assimakopoulos, N., Dimitriou, N. and Theocharopoulos I. 2010. Business intelligence systems for virtual enterprises: A cybernetic approach. International Journal of Applied Systemic Studies. 3:(4) pp. 374-388.

Chatzoglou, P., Theriou, N., Dimitriadis E. and Aggelides V. 2007. Software project management and planning: The case of the Greek IT sector. International Journal of Applied Systemic Studies. 1:(3) pp. 305-316.

Curtis, R. 2000. E-commerce Database Design. Available at:

http://www.princeton.edu/ rcurtis/ultradev/ecommdatabase.html

Darwish, H. 2009. Emarketing Manage your customer database. Available at: http://emarketingassociation.ning.com/profiles/blogs/e-marketing-manage-your

Department of Trade and Industry of United Kingdom. 2004. Achieving Best Practice in your Business. Emarketing. Available at: http://dc423.4shared.com/doc/SASKJdTT/preview.html

DigitSmith. 2006. Ecommerce definition and types of ecommerce. Available at: http://www.digitsmith.com/ecommerce-definition.html

Elmasri, R. and Navathe, S.B. 2004. Fundamentals of Database Systems. 4 th ed. Addison Wesley.

Espejo, R. 2008. Observing organizations: The use of identity and structural archetypes. International Journal of Applied Systemic Studies. 2:(1/2) pp. 6-24.

Eszes, I. 2010. An introduction to internet marketing. Available at: http://www.eszes.net/eLibrary/intmktgch1.pdf

Fathian, M., Akhavan, P. and Hoorali, M. 2008. E-readiness assessment of non-profit ICT SMEs in a developing country: The case of Iran. Technovation. 28:(9) pp. 578-590.

Gadenne, D. and Sharma, B. 2009. Management factors of Australian SMEs and their association with firm performance. International Journal of Quality \& Reliability Management. 26:(9) pp. 865-880.

Garengo, P., Biazzo, S., Simonetti, A. and Bernardi, G. 2005. Benchmarking on managerial practices: A tool for SMEs. The TQM Magazine. 17:(5) pp. 440-455.

Geld, S. 2003. Advantages of email. Available at: http://thephantomwriters.com/free_content/d/g/email_advantages.shtml

Griffin, M. 2000. Emarketing Planning: Accountability and Emetrics. Embelix Software. Available at http://www.templatezone.com/pdfs/ems_whitepaper.pdf

Haramis, I.E.C. 2009. Evaluate Your Financial Situation. Available at: http://www.greekshares.com/evaluate.php

Ho, G.T.S., Lee, C.K.M., Lau, H.C.W. and Ip, A.W.H. 2007. An online Decision Support System for inventory management. International Journal of Product Development. 4:(3/4) pp. 351-365.

Hu, E., Abley, W. and Zou, L. 2008. Environmental related decision making using the Interlink Decision Making Index (IDMI). International Journal of Environment and Waste Management. 2:(3) pp. 257-266.

Jeffery, K. 2008. Grids, databases and information systems engineering research. In EDBT 2008: Proceedings of the $9^{\text {th }}$ International Conference on Extending Database Technology, Heraklion, Crete, Greece, pp. 3-16.

Kohtamaki, M., Tornikoski, E., and Varamaki, E. 2009. The strategic management competence of Small and Medium-sized growth firms. International Journal of Entrepreneurship and Small Business. 7:(1) pp. 139-150.

Lloyd, S. 2007. Database marketing and management for SMEs. Available at:

http://www.smartcompany.com.au/construction-and-engineering/database-marketing-and-management-forsmes.html

Mc Fadden, F.R., Hoffer, J.A. and Prescott, M.B. 1999. Modern Database Management. 5 th ed. Addison Wesley Longman, Inc.

Pearson M. 2008. Strategic plan implementation: How to make good things happen and better things happen consistently. Available at: http://www.di.net/articles/archive/strategic_plan_implementation_how_to/

Petrovic, D. 2010 What is e-marketing? Available at: http://analogik.com/articles/231/e-marketing

Post, G. and Kagan, A. 2001. Database Management Systems: Design considerations and attribute facilities. The Journal of Systems and Software. 56 pp. 183-193. 
Pratt, P.J. and Adamski, J.J. 1991. Database Systems: Management and Design. 2 nd ed. South Western Publishing Company. Boston. MA.

Quirk eMarketing. 2006. What is Emarketing and How is it Better than Traditional Marketing? Available at: http://www.quirk.biz/resources/88/What-is-eMarketing-and-how-is-it-better-than-traditional-marketing

Sagheb-Tehrani, M. and Manousaridis, Z. 2007. Sustained growth development through effective information systems development. International Journal of Applied Systemic Studies. 1:(4) pp.348-360.

Schlaginhaufen T. 2007. Design and Implementation of a Database Client Application for Inserting, Modifying, Presentation and Export of Bitemporal Personal Data. Diploma Thesis, Department of Informatics, Univ. of Zurich.

Sohrabi, B., Jafarzadeh, M.H. and Ahmadabadi, E.N. 2010. A method for measuring the alignment of ERP systems with enterprise requirements: Application of requirement modeling. International Journal of Management and Enterprise Development. 9:(2) pp. 158-178.

Tansel, A.U. 2009. Managing Temporal Data. Baruch College - CUNY. USA.

Thassanabanjong, K., Miller, P. and Marchant, P. 2009. Training in Thai SMEs. Journal of Small Business and Enterprise Development. 16:(9) pp. 678-693.

The National B2B Centre. 2011. Develop an E-marketing Plan. Available at: http://www.businesslink.gov.uk/bdotg/action/layer?topicId=1075384972

Tsekouropoulos, G., Andreopoulou, Z., Seretakis, A., Koutroumanidis, T. and Manos, B. 2011. Optimizing Emarketing Criteria for Customer Communication in Food and Drink Sector in Greece. International Journal of Business Information Systems. 9:(1) pp. 1-25.

Tsekouropoulos, G., Andreopoulou, Z., Koliouska, C., Koutroumanidis, T., Batzios, C. And Lefakis, P. 2012. Marketing Policies through the Internet: The Case of Skiing Centers in Greece. In EBEEC 2012: Proceedings of the $4^{\text {th }}$ International Conference on The Economies of Balkan and Eastern Europe Countries in the changed world, Sofia, Bulgaria, May 11-13.

Vowles, J. 2001. Database Management Systems (DBMS). Available at: http://www.bibliotech.com/html/databases.html

Wilson, K. 2007 The Importance of a Properly Used Microsoft Access Query. Available at: http://articledirectoryfree.com/articles/computers/software/the-importance-of-a-properly-used-microsoftaccess.html

Wu, C., Kao, S. and Wu, C. 2006. Data-based Decision Support Technology Used in the Financial Service Industry. International Journal of Financial Services Management. 1:(4) pp.422-437.

Ziegler, P. and Dittrich, K. 2007. Data Integration-Problems, Approaches and Perspectives. Database Technology Research Group, Department of Informatics, University of Zurich. 